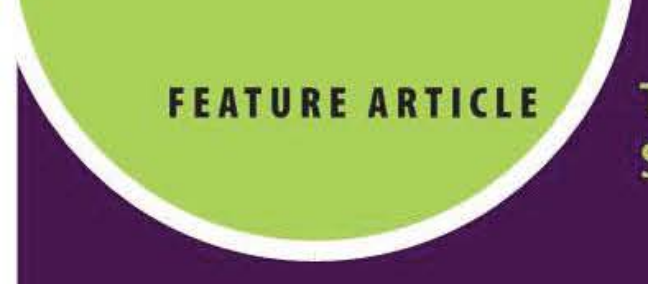

\title{
The Discovery of Insulin: A Case Study of Scientific Methodology
}

WILliam D. STANSFiELD

\section{Abstract}

The nature of scientific research sometimes involves a trial-and-error procedure. Popular reviews of successful results from this approach often sanitize the story by omitting unsuccessful trials, thus painting the rosy impression that research simply follows a direct route from hypothesis to experiment to scientific discovery. The discovery of insulin is a classical case study in this genre that begs for an explanation to our students because it is so often ignored or misrepresented even in biology and physiology textbooks.

Key Words: Diabetes; animal welfare; experimental mistakes; Nobel Prize; self-experimentation; trial-and-error procedure.

NABT members are fortunate to have Maura Flannery as editor of the "Biology Today" department of the ABT. I have always enjoyed and learned from her editorials. In the October 2005 issue, she discussed the "diabetes mystery" and seemed to imply that the history of the discovery of insulin is "too well known to biology teachers to be repeated here" (Flannery, 2005: p. 503). Flannery has written extensively about diabetes mellitus elsewhere and perhaps overestimates the knowledge of her colleagues in this respect. If I had not been assigned to teach a graduatelevel course in the history of biology, I am quite certain that I would not have known anything about the discovery of insulin. I wondered if my formal education was atypical. Perhaps there has been a tendency, in many educational institutions from which prospective teachers graduate, to slight the historical aspects of their discipline in order to accommodate the increased load of new information they feel compelled to cram into their curricula. If this is true, there may be many other biology teachers who are unaware of the history of the discovery of insulin and how it merited a Nobel Prize in Physiology or Medicine (1923) for two of its researchers. I looked through several physiology and general biology textbooks and found few (e.g., Keeton, 1967: pp. 327-328) that even mention Frederick G. Banting and Charles H. Best, let alone describe their famous experiments with dogs. They discovered that the dog's pancreas contains an "anti-diabetic factor," which they extracted and used successfully to treat diabetes, first in dogs and later in humans. Even the textbook The Human Body: Its Anatomy and Physiology (Best \& Taylor, 1963) says nothing about these experiments. Was Best trying too. hard to avoid the appearance of self promotion in his book by not mentioning Banting or himself and the parts they played in the discovery of insulin? So where are our teachers going to be exposed to the insulin story if not here in the pages of the $A B T$ ?

\section{O Biology of the Pancreas}

To understand the history of the discovery of insulin, it helps to first become familiar with the basic structures (anatomy) and functions (physiology) of the pancreas. The pancreas lies in the abdominal cavity, It consists of two major classes of cells; glandular (ascinar) exocrine cells that secrete digestive enzymes; cells that produce hormones are called endocrine cells. Hormones are secreted into the bloodstream and carried to all parts of the body. Enzymes in the pancreatic juice flow into a long pancreatic duct that merges with the common bile duct and opens into the duodenal mucosa. The pancreatic juice contains enzymes for digesting proteins (trypsin), carbohydrates (amylopsin), lipids (steapsin), and rennin for coagulating milk. It also secretes carbonate and sodium bicarbonate. All enzymes of pancreatic juice are secreted in an inactive form called zymogens; they become activated in the alkaline environment of the small intestine. Trypsin is secreted as the zymogen trypsinogen; it is converted in the intestine into the active enzyme trypsin by an enzyme called enterokinase. The endocrine cells of the pancreas form small clusters throughout the organ called islets or islands of Langerhans (named for Paul Langerhans, who discovered them in 1869). Islet cells that secrete the hormone-like substance glucagon are termed alpha cells; those that secrete the hormone insulin are called beta cells. Glucose is not stored in the body as glucose. Insulin stimulates the conversion of glucose to glycogen (animal starch) mainly in liver and muscle 
tissue and stimulates the entry and combustion of glucose in all tissue cells. Glucagon stimulates the conversion of glycogen back to glucose for use by other cells as needed.

\section{O The Insulin Story}

The six major components of a journalistic report are "who, what, when, where, why, and how." Much of the popular account of the discovery of insulin can be summarized here in this manner. It offers an efficient way whereby readers can test their own knowledge about the history of the discovery of insulin prior to reading this article. It also might be used as a class exercise after students are given the essentials of the insulin story via a lecture or handout to assess the effectiveness of the prior exposure.

Q. When (year[s]) was an effective treatment for diabetes discovered?

A. 1921 (dogs); 1922 (humans)

Q. Where (city, country) were these experiments conducted?

A. Toronto, Ontario, Canada (dog: Department of Physiology, University of Toronto; human: Toronto General Hospital)

Q. What were the major objectives of these experiments?

A. To discover whether the pancreas produces a substance with anti-diabetic activity, to extract and purify this substance, and to successfully treat a diabetic dog with the extract, and then move on to clinical treatment in humans

Q. Who were the two people awarded a Nobel Prize in Medicine or Physiology for their work in finding a treatment for diabetes? Each of these prize winners shared their award money with another person who they felt was equally meritorious. Name these laureates and indicate the most important contribution(s) made by each of these four individuals. Also note with whom the prize winners shared their award money.

\section{A. Nobel Prize Winners:}

(1) Frederick Grant Banting - designed the experiments, performed the required surgery, and prepared pancreatic extracts for treating diabetes; he shared his prize money with Best

(2) John James Rickard Macleod - provided equipment, animals, advice, and guidance for the experiments; he shared his prize money with J. B. Collip

A. Others:

(1) Charles Herbert Best - assayed the test animal's blood and urine for sugar content just before and at intervals after the treatment began

(2) James Bertram Collip - produced commercial quantities of purified insulin

Q. Explain how the experimental procedures were conducted in four major steps. Specify the experimental animals used at each step.

A. Four major steps in the initially proposed experimental procedure are

(1) Ligate the pancreatic ducts of a normal dog (the source animal); wait 6 weeks.

(2) Remove the pancreas from the source dog; mince and grind tissue in ice-cold isosmotic solution; filter the extract.
(3) Remove the pancreas from a second normal dog (the test animal); wait for its blood sugar (glucose) level to rise above normal.

(4) Inject pancreatic extract into the test dog; monitor at intervals for drop in blood sugar level.

Q. Why was step 1 of the experimental procedure deemed necessary?

A. Banting thought that ligating the pancreatic ducts of the source animal would allow the acinar cells to degenerate; otherwise, pancreatic enzymes might digest the anti-diabetic substance if it was present in the pancreatic extract. He also thought that ligation of the ducts might allow the anti-diabetic substance to accumulate, thus increasing its concentration in the extract to a level that would be physiologically active when injected into the diabetic test animal.

\section{O Discussion \& Critique}

The above Q \&A test may represent common knowledge (or misconception) to many people who know at least something of the story. However, the full story is surprisingly quite different and needs to be understood by biology teachers and students as an example of how misleading or limited many biology and physiology textbook accounts of the discovery of insulin can be. The most definitive source I found is The Discovery of Insulin (1982) by Michael Bliss.

New discoveries in science are dependent on the work of predecessors, many of whom are seldom given the credit they deserve. All researchers are metaphorically "standing on the shoulders of giants." In 1889, two Germans, Oskar Minkowski and Joseph von Mering, removed the pancreas from a dog and observed results that resembled diabetes. They reasoned that the pancreas must produce an anti-diabetic substance. Previous workers had ligated or cut the pancreatic ducts and saw no sign of diabetes (Bliss, 1982: p. 26).

Georg Ludwig Zuelzer, a young internist in Berlin, injected an extract of pancreas into depancreatized dogs and reduced the sugar excreted in the urine. On 21 June 1906, he injected his pancreatic extract under the skin of a 50 -year-old diabetic patient and observed improved clinical symptoms. He treated other patients with varied success in suppressing glycosuria, but he did so at the cost of severe toxic side effects (Bliss, 1982: pp. 29-30).

In 1916, the Romanian physiologist Nicolas C. Paulescu (18691931) was able to extract a crude extract of bovine pancreas in salted water and removed some impurities with sodium hydroxide and hydrochloric acid. He injected it into a diabetic dog and found that it normalized the blood sugar level. His work was interrupted during World War I. During 1921, Paulescu published at least two papers on his anti-diabetic pancreatic hormone (he called it "pancreine") experiments at the Romanian Section of the Society of Biology in Paris. This was about the same time that Banting began his experiments. Did Banting read Paulescu's 1921 papers before he began his own experiments? Because intravenous injections of his pancreatic extracts caused toxic side effects in his dogs, Paulescu administered his extract rectally to humans via a rubber tube; the results were no different from those produced by control doses of saline alone. What made Paulescu think that a pancreatic extract of a bovine would be physiologically active in a genetically unrelated animal $(\mathrm{dog})$ ? Foreign tissue transplants often are rejected by the immune system of the recipient. Even within the same species (e.g., humans), heterologous transplants of tissue or blood may be subject to rejection. 
Frederick Grant Banting (1891-1941) was a young physician (surgeon) with a private practice in London, Ontario. How much of the literature on diabetes he read prior to his experiments is not known. In 1920, however, Banting read a paper by the American pathologist Moses Barron, who reported a rare case of a pancreatic stone (lithiasis) that had obstructed the main pancreatic duct of a human cadaver; all acinar cells of the pancreas disappeared (atrophied), but most islet cells remained, results similar to those produced by ligation of pancreatic ducts, as reported in the literature by others (Bliss, 1982: p. 49). This observation may have been the stimulus for Banting to envision ligating pancreatic ducts of normal dogs to protect the external secretions (digestive enzymes) from digesting the internal secretion(s) (hormone|s]) while preparing extracts for administration to diabetic dogs.

In 1921, Banting took his idea to John James Rickard Macleod (1876-1935), professor of physiology at the University of Toronto, because Macleod was an internationally known expert on carbohydrate metabolism. Macleod was not impressed with Banting's idea. Banting obviously had little knowledge about previous experiments of this kind and had no training in experimental physiological research. Eventually Banting convinced Macleod to provide him with a small surgical room, dogs, and a helper to perform blood and urine glucose tests.

Charles Herbert Best (1899-1978) had just graduated with a B.A. from the University of Toronoto's Honours Physiology and Biochemistry course. He volunteered to help Banting obtain glucose readings from blood and urine in his dog experiments. After many early failures, Banting succeeded in extracting a pancreatic solution that contained enough anti-diabetic substance from fetal calf pancreas to lower the blood sugar in a dog made diabetic by pancreatectomy. This meant no more duct ligations and no more shortages of extract, because fetal calves were readily available from meatprocessing plants. However, the crude extracts proved somewhat toxic and would not be suitable for testing on humans. The extraction procedure was improved when fetal calf extracts were passed through an unglazed porcelain filter (Berkefeld filter) to remove bacterial contaminants.

On 23 November 1921, Banting injected himself subcutaneously with the new extract. He observed no adverse effects, but no blood was taken for testing. Banting introduced one extract into his own digestive system via a stomach tube and also observed no adverse effect. On 11 December 1921, Banting removed a whole dog pancreas, and Best prepared an extract in alcohol. When he injected the extract back into the donor dog, the animal's blood sugar level dropped. This meant that no more degenerated pancreases and no more fetal pancreases were needed. On 11 January 1922, a 14-year-old dia-

betic boy, Leonard Thompson, was injected in the buttocks (intramuscular?) with Banting and Best's whole beef pancreas extract, with disappointing results. Macleod had previously invited the biochemist James Bertram Collip (1892-1965) from the University of Alberta to join the Toronto team to help purify the extracts of toxic substances and concentrate the active principle for use in diabetic humans. About 16 January 1922, Collip succeeded in precipitating the active principle in whole beef pancreas at a critical concentration of alcohol ( $95 \%$; the isoelectric point). He tested an aqueous solution of the precipitate on rabbits, with success in reducing blood sugar. Collip's extract was then given to Thomson on 23 January 1922 . This time there was no doubt about the effectiveness and safety of the treatment (Bliss, 1982: pp. 120-121).

Banting and Best published their first paper in 1922 on the successful use of a pancreatic extract for normalizing blood sugar (glucose) levels (glycemia) in diabetic dogs. This paper made direct reference to Paulescu's article but misquoted that article as follows: "He [Paulescu] states that injections into peripheral veins produce no effect and his experiments show that second injections do not produce such marked effect as the first," which is not what Paulescu found out or presented. Later on, Banting said that

I regret very much that there was an error in our translation of Professor Paulescu's article, I cannot recollect, after this length of time, exactly what happened.... I do not remember whether we relied on our own poor French or whether we had a translation made. In any case I would like to state how sorry I am for this unfortunate error. (http:// en.wikipedia.org/wiki/Nicolae_Paulescu)

Where did Banting get the idea that tying off the pancreatic duct might cause the acinar cells to degenerate and the pancreatic enzymes to disappear or become inactive? What made him think that the anti-diabetic substance would accumulate in the ligated pancreas instead of disappearing along with the pancreatic enzymes? Do liver cells and bile degenerate if the bile duct is ligated? Why did Banting choose to wait 6 weeks (instead of some shorter or longer duration) before attempting to extract insulin from the source pancreas? His first attempt was unsuccessful because the relatively stiff cat-gut ligature loosened and failed to block the ducts. Six weeks were wasted. Silk thread gave better results after that.

At the time Banting was doing his experiments, the chemical structure of insulin was not known; it could have been protein, lipid, carbohydrate, or another form of matter. Biomacromolecules, such as proteins, are more labile (subject to degradation) when warm and when contaminated by bacteria than when cold and sterile. Macleod advised Banting to keep his extracts cold, and potentially more physiologically stable, in the heat of the Ontario summer. Whether his predecessors did likewise is debatable, especially before the advent of refrigeration.

Although Best and Taylor (1963: p. 371) do not discuss the experiments of Banting and Best, they do discuss how the hormone secretin is produced by the mucous membrane of the intestine and is carried by the blood to the pancreas, where it stimulates the secretion of pancreatic juice. They also give some details of how secretin can be extracted from intestinal tissue:

If the wall of the intestine of any anim ground up with water and then filtered so as to free it of solid particles, the clear fluid so obtained will be found to contain large amounts of secretin; for when the fluid is injected into the blood of another animal, a very abundant secretion of pancreatic juice results.

Insulin may have been extracted by Banting and Best from pancreatic tissue in essentially the same manner as described here for the extraction of secretin from the intestinal membrane. Another intestinal hormone that stimulates the secretion of pancreatic juice is called pancreozymin. Secretin mainly induces secretion of the water and salts of the pancreatic juice, whereas pancreozymin mainly stimulates secretion of enzymes. 
As Bliss (1982: pp, 278-279) relates,

There were eight distinct and essential steps or stages leading to the production of an insulin that was sufficiently pure to be used in the treatment of diabetes and which could be produced in adequate quantity to meet the urgent demand. The first of the steps was the use of alcohol in extracting the hormone from the minced pancreas. This was announced by Zuelzer in Berlin in 1907. It was rediscovered by the Toronto investigators in 1921, who did not know of Zuelzer's work. The second was a method of determining the amount of sugar quickly and accurately in a small quantity of blood. This was devised by Lewis and Benedict in New York in 1913. The third was the discovery of Kleiner and Meltzer in 1915 that an aqueous extract of the normal pancreas injected into the veins of a normal dog reduced hyperglycemia as well as glycosuria. The fourth step was the discovery that the active principle was maximally insoluble in 95 percent alcohol. This was made by Banting, Best and Collip in December 1921. The fifth was the preparation by Collip of the first relatively non-toxic insulin to be used in the treatment of diabetes (January 1922) with success. The sixth step was the physiological assay based on Collip's observation (February 1922 [actually December]) that insulin in adequate amount usually produced convulsions in normal rabbits when the blood sugar fell to $46 \mathrm{mg}$ per $100 \mathrm{cc}$. The seventh was the discovery by Doisy, Somogyi and Shaffer of St. Louis, that insulin was precipitated at the iso-electric point.... The eighth and final step was the development of methods of large-scale production by the chemical engineers of the Eli Lilly Co. of Indianapolis in 1922-23.

A devastating criticism of Banting and Best's work by Dr. Ffrangcon Roberts was published in the 16 December 1922 issue of the British Medical Journal. He opined that Banting's hypothesis that duct ligation was necessary for trypsin-producing cells to atrophy before making an extract of the internal secretion was false. Trypsin is not active in the pancreas. It is produced as trypsinogen, and becomes acted on by another ferment - enterokinase, secreted by the small intestine. There was no physiological basis for their duct experiments (Bliss, 1982: p. 203).

Roberts also pointed out that Banting and Best had misinterpreted their experiment on 18-19 August 1921. Their data show that extracts from whole pancreases were more effective and more lasting than those made from degenerated pancreases. However, Banting and Best claimed that whole-gland extract was weaker and, thus, reinforced their hypothesis (Bliss, 1982; p. 204). Roberts concluded that

The production of insulin originated in a wrongly conceived, wrongly conducted, and wrongly interpreted series of experiments.... Banting himself never seems to have read or known about Roberts' criticisms.... For the next thirty years no one else studied Banting and Best's experiments carefully and critically. (Bliss, 1982: pp. 205-207)

During the experiments of Banting and Best, it was found that insulin could be extracted from a whole, normal, unligated pancreas and that the pancreases of fetal cattle or pigs are just as effective as those of dogs as a commercial source of insulin. Fetal cells in the islets of Langerhans develop sooner than the acinar cells, so there would be no digestive enzymes to destroy the insulin during the extraction procedure, and no need to perform duct ligations. In hindsight, the dog experiments were probably unnecessary for the discovery of insulin. However, those early experiments eventually led to the clinical use of insulin. This would almost certainly have been discovered sooner or later by other workers. But think of how many people might have suffered and died of diabetes before this knowledge would become available without the dog experiments.

On what basis do scientists choose the organisms for their experiments? In the case of diabetes, why were dogs chosen? Chimpanzees are more closely related to humans than dogs are, but their use in experiments has serious ethical and economic considerations. When doing surgery, size matters. Removal of a pancreas is an easier job on a large dog than on a small rabbit or a cat. Imagine surgical ligation of pancreatic ducts in a rat! Also, domestic dogs are more receptive to injections and periodic blood sampling than pigs or calves, and they require less food and space for housing (lower costs). Hundreds of unligated rabbits were used by Collip to test the potency, dosage, and safety of his extracts.

Students may want to know what happened to the dog that had its pancreas removed as a source for extraction of insulin. It must be remembered that in those early days there were fewer animal welfare laws than we have today. Science ethics should always evaluate the need to perform experiments on animals in terms of their potential medical or veterinary benefits. Many dogs that cannot find a home or cannot be housed indefinitely by animal shelters must be euthanized or else die of starvation and neglect. Is it not more ethical to humanely euthanize an animal in the search for a potential medical treatment than to allow an animal to suffer and die in this way?

If the discovery of insulin is defined as the time the first extracts lowered the blood sugar of dogs, then the priority for the discovery belongs to Zuelzer, Scott, Murlin, Paulescu, and others. But if insulin was discovered when an extract first had anti-diabetic effects on a human (although with toxic side effects), Zuelzer had done this earlier. According to Bliss (1982: p. 209),

\footnotetext{
There are really only two tenable views of the moment of discovery. One is that insulin had been discovered when a non-toxic preparation of it reduced the cardinal symptoms of diabetes in a human being. That happened with Collip's insulin in January 1922.
}

The other view is that insulin had been discovered when convincing evidence of its existence had been presented, leading back to Minkowski and von Mering in 1889. Perhaps the most widely 
accepted date of announcement of the discovery of insulin is 3 May 1922, when, at a meeting of the Association of American Physicians, convincing evidence was presented by the Toronto team of Banting, Best, Collip, Campbell, Fletcher, Macleod, and E. C. Noble (all of whom were part of the discovery team) and accepted by their peers (Bliss, 1982: p. 210).

\section{O Teaching Tip}

As parting words in her editorial, Flannery says

Keep this in mind when you are planning examples to whet your students' appetites

meritus Professor of Biological Sciences at

University, San Luis Obispo, CA 93407; mailing

San Luis Obispo, CA 93405-1123; e-mail:

\section{References}

Banting, F.G. \& Best, C.H. (1922). The internal secretion of the pancreas. Journal of Laboratory and Clinical Medicine, 7, 256-271.

Best, C.H. \& Taylor, N.B. (1963). The Human Body: Its Anatomy and Physiology, $4^{\text {th }}$ Ed. New York, NY: Holt, Rinehart and Winston.

Bliss, M. (1982). The Discovery of Insulin. Chicago, IL: University of Chicagio Press.

Flannery, M. (2005). Questions, large \& small. American Biology Teacher, 67, 498-504.

Keeton, W.T. (1967). Biological Science. New York, NY: W.W. Norton.

Roberts, F. (1922). Insulin. British Medical Journal, 16 December, 1193-1194.

for the intrigues of biology. Chose either what interests you, or what you think will interest them. In the best case, the examples can do both. (Flannery, 2005: p. 504)
WILLIAM D. STANSFIELD is California Polytechnic State address: 653 Stanford Drive wstansfi@calpoly.edu. 